Tạp chí Nghiên cứu Kinh tế và Kinh doanh Châu Á
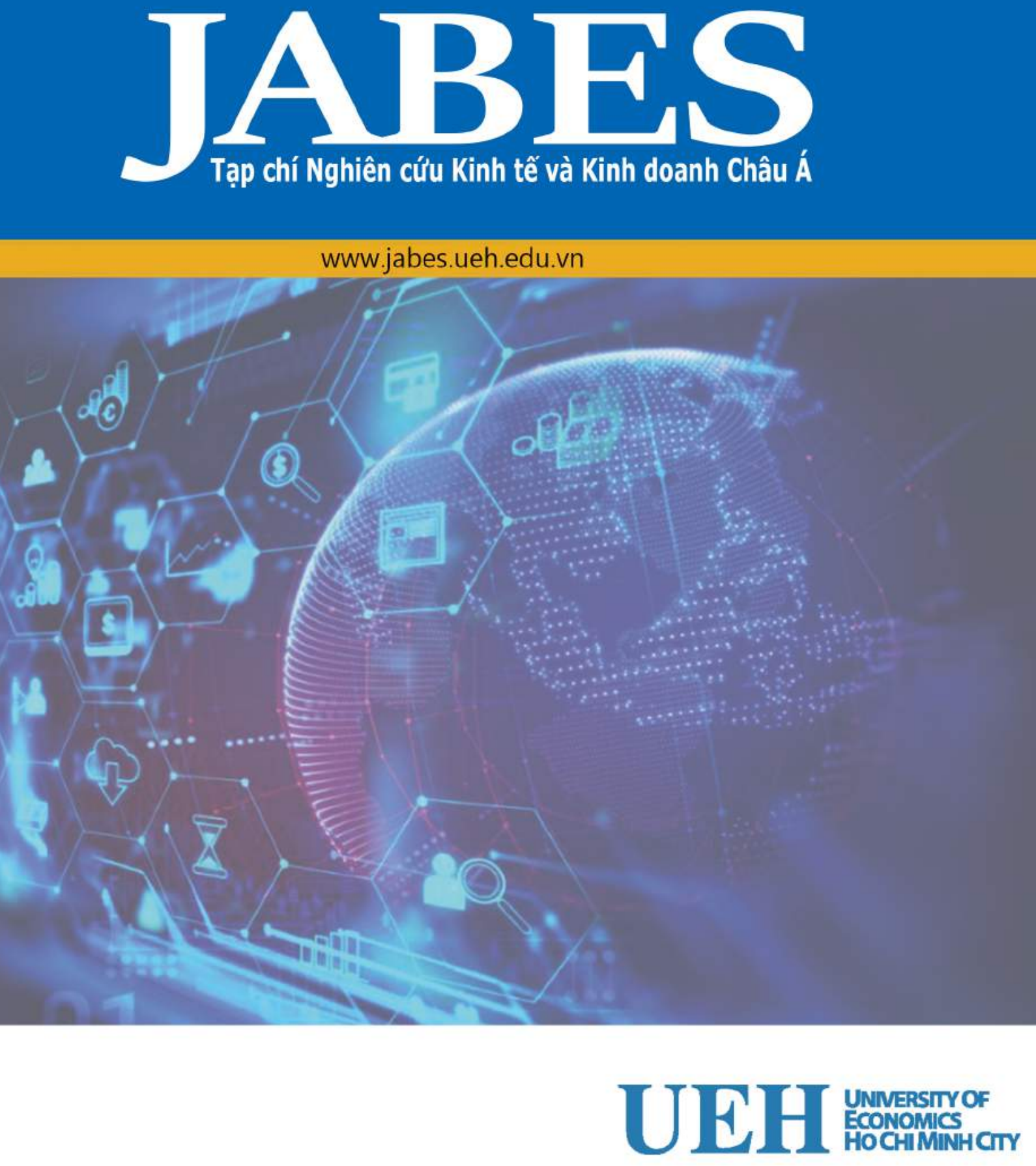


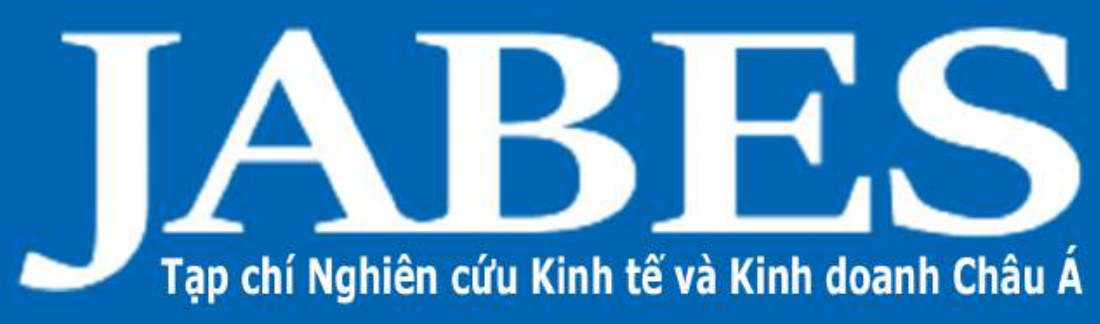

ISSN 2615 - 9104

Nguyễn Thị Ngọc Trang \& Bùi Kim Phương

Các yếu tố ảnh huơơng đến chất luợng lợi nhuận của các công ty niêm yết tại Việt

Nam.

Đinh Thị Thu Hồng \& Nguyễn Trí Minh

Nộxáu và vấn đề rủi ro đạo đức trong hệ thống ngân hàng thuoong mại Việt Nam

Nguyễn Thị Hồng Vinh \& Nguyễn Minh Sáng

Nghiên cứu tác động của các yếu tố vĩ mô và đặc thù ngân hàng đến nợ xấu: Bằng chứng thực nghiệm của các ngân hàng thương mại Đông Nam Á.....

Phạm Thị Bích Ngọc \& Trương Thị Thùy Trang

Ảnh hương của hỗ trọ thuoong mại tù Mỹ đến xuát khẩu thủy sản vào thị truờng Mỹ: Truờng hợp các quốc gia thu nhập thấp và trung bình.. 


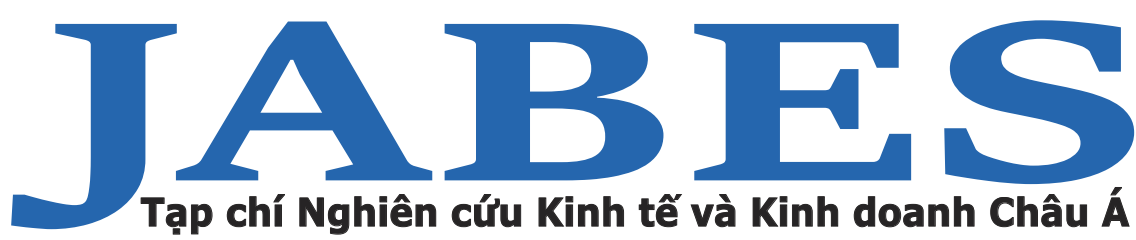

ISSN 2615 - 9104

Nguyễn Thị Ngọc Trang \& Bùi Kim Phương

Các yếu tố ảnh huơong đến chất luợng lợi nhuận của các công ty niêm yết tại Việt Nam.

Đinh Thị Thu Hồng \& Nguyễn Trí Minh

Nợ xấu và vấn đề rủi ro đạo đức trong hệ thống ngân hàng thuơng mại Việt Nam

Nguyễn Thị Hồng Vinh \& Nguyễn Minh Sáng

Nghiên cứu tác động của các yếu tố vĩ mô và đặc thù ngân hàng đến nợ xấu: Bằng chưng thực nghiệm của các ngân hàng thuơng mại Đông Nam Ả

Phạm Thị Bích Ngọc \& Trương Thị Thùy Trang

Anh hương của hỗ trọ thuơng mại tù̀ Mỹ đến xuất khẩu thủy sản vào thị truờng Mỹ:

Trường hợp các quốc gia thu nhập thấp và trung bình. 


\title{
Nghiên cứu tác động của các yếu tố vĩ mô và đặc thù ngân hàng đến nợ xấu: Bằng chứng thực nghiệm của các ngân hàng thương mại Đông Nam Á
}

\author{
NGUYỄN TH! HỒNG VINH ${ }^{a}$, NGUYỄN MINH SÁNG b \\ $a, b$ Trường Đại học Ngân hàng TP. Hồ Chí Minh
}

\begin{tabular}{|c|c|}
\hline T H Ô N G T I N & T Ó $\mathrm{M}$ T Ắ T \\
\hline $\begin{array}{l}\text { Ngày nhận: 19/09/2018 } \\
\text { Ngày nhận lại: 23/10/2018 } \\
\text { Duyệt đăng: 24/10/2018 } \\
\text { Mã phân loại JEL: } \\
\text { G21, E32, E44 } \\
\text { Từ khóa: } \\
\text { Ngân hàng; } \\
\text { Dữ liệu bảng; } \\
\text { Yếu tố kinh tế vĩ mô; } \\
\text { Yếu tố đặc thù; } \\
\text { Nợ xấu; } \\
\text { Đông Nam Á. }\end{array}$ & $\begin{array}{l}\text { Mục tiêu của bài nghiên cứu là đánh giá tác động của các yếu tố vĩ mô } \\
\text { và yếu tố đặc thù đến nợ xấu của hệ thống ngân hàng thương mại ở } \\
\text { các quốc gia khu vực Đông Nam Á. Nghiên cứu sử dụng phương pháp } \\
\text { ước lượng GMM hệ thống thông qua dữ liệu từ } 204 \text { ngân hàng thương } \\
\text { mại ở các quốc gia khu vực Đông Nam Á trong giai đoạn } 2010-2015 . \\
\text { Kết quả nghiên cứu cho thấy nợ xấu của ngân hàng thương mại các } \\
\text { nước trong khu vực chịu tác động bởi cả yếu tố vĩ mô và yếu tố đặc } \\
\text { thù. Theo đó, nợ xấu hiện tại của các ngân hàng trong khu vực Đông } \\
\text { Nam Á chịu tác động ngược chiều của các yếu tố là tỷ suất sinh lợi, tốc } \\
\text { độ tăng trưởng tín dụng, tỷ lệ cho vay/tiền gửi, quy mô ngân hàng } \\
\text { nhưng cùng chiều với nợ xấu trong quá khứ và vốn chủ sở hữu. Đặc } \\
\text { biệt, các yếu tố vĩ mô có ảnh hưởng đáng kể đến chất lướng cho vay } \\
\text { của các ngân hàng thương mại. Kết quả cũng tìm thấy biến ngân sách } \\
\text { và thuế thu nhập tác động có ýnghĩa thống kê đối với nợ xấu. Qua đó, } \\
\text { các nhà quản trị ngân hàng có thể xem xét tác động của các biến đặc } \\
\text { thù ngân hàng như là các chỉ số cảnh báo sớm. Kết quả này cũng giúp } \\
\text { ích cho các nhà hoạch định chính sách trong việc thiết kế các chính } \\
\text { sách tài khóa và vĩ mô an toàn, trong đó cần chú trọng đánh giá tác } \\
\text { động của các chính sách vĩ mô đến rủi ro tín dụng của các ngân hàng. }\end{array}$ \\
\hline
\end{tabular}

\footnotetext{
a vinhnth@buh.edu.vn, * Tác giả liên hệ.

bsangnm@buh.edu.vn

Trích dẫn bài viết: Nguyễn Thị Hồng Vinh, \& Nguyễn Minh Sáng. (2018). Nghiên cứu tác động của các yếu tố vĩ mô và đặc thù ngân hàng đến nợ xấu: Bằng chứng thực nghiệm của các ngân hàng thương mại Đông Nam Á. Tạp chí Nghiên cứu Kinh tế và Kinh doanh Châu Á, 29(7), 37-51
} 


\begin{abstract}
Macroeconomic
determinants;

Bank-specific

determinants;

Non-performing loan;

Southeast Asia.
\end{abstract}

\title{
1. Đặt vấn đề
}

Nợ xấu được xem là một trong những yếu tố gây ảnh hưởng bất lợi đến sự ổn định và tăng trưởng đồng thời cũng liên quan đến khủng hoảng tài chính - ngân hàng ở cả thị trường mới nổi và các nền kinh tế phát triển. Trong khu vực Đông Nam Á, nợ xấu vượt 4,759\% năm 2010 và trên $3 \%$ trong giai đoạn 2010-2015. Trong Bảng 1, tỷ lệ nợ xấu trung bình trong giai đoạn nghiên cứu cao nhất là ở các ngân hàng tại Philippines và Thái Lan với tỷ lệ lần lượt là $11,18 \%$ và $3,417 \%$ trong khi các ngân hàng Singapore có tỷ lệ nợ xấu rất thấp, ở mức dưới $1 \%$. Việc xem xét các yếu tố nào ảnh hưởng đến nợ xấu của các ngân hàng hương mại (NHTM) là rất quan trọng trong việc ngăn ngừa nợ xấu trong tương lai. Do đó, nhóm tác giả tiến hành nghiên cứu thực nghiệm ảnh hưởng của các yếu tố vĩ mô và các yếu tố đặc thù của nợ xấu ngân hàng ở khu vực Đông Nam Á. 


\section{Bảng 1}

Tỷ lệ nợ xấu của các quốc gia Đông Nam Á giai đoạn 2010-2015 (Đơn vị tính: \%)

\begin{tabular}{lllllllll}
\hline Năm & Indonesia & Campuchia & Philippines & Singapore & Lào & Malaysia & Thái Lan & Việt Nam \\
\hline 2010 & 5,700 & 4,713 & 10,574 & 0,900 & & & 4,656 & 2,012 \\
2011 & 2,440 & 4,047 & 10,937 & 0,739 & 5,220 & 5,437 & 4,070 & 2,450 \\
2012 & 2,177 & 2,946 & 11,428 & 0,739 & 1,540 & 2,526 & 2,992 & 3,393 \\
2013 & 2,256 & 2,126 & 12,813 & 0,705 & 1,740 & 1,609 & 2,830 & 3,010 \\
2014 & 2,442 & 2,284 & 14,474 & 1,120 & 1,996 & 1,523 & 2,892 & 2,522 \\
2015 & 4,220 & 2,381 & 6,855 & 0,790 & 1,162 & 1,929 & 3,060 & 1,877 \\
$\begin{array}{l}\text { Giá trị } \\
\text { trung bình }\end{array}$ & 3,206 & 3,083 & 11,180 & 0,832 & 2,332 & 2,605 & 3,417 & 2,544 \\
\hline
\end{tabular}

Nguồn: Nhóm tác giả tính toán từ Bankscope ${ }^{1}$, số liệu thu thập năm 2016.

Nghiên cứu này đóng góp vào cơ sở các nghiên cứu thực nghiệm như sau:

Đầu tiên, hầu hết các nghiên cứu trước đây như Berger và DeYoung (1997), Salas và Sarina (2002), Louzis và cộng sự (2010) cùng Anastasiou và cộng sự (2016) thường tập trung vào các trường hợp của Mỹ hoặc châu Âu. Mặc dù khu vực Đông Nam Á đã trở thành một khu vực kinh tế quan trọng nhưng nợ xấu ngân hàng ở khu vực Đông Nam Á vẫn chưa được nghiên cứu đầy đủ và toàn diện. Trong khả năng tiếp cận của nhóm tác giả, đến nay vẫn chưa có nghiên cứu nào thực hiện cho các NHTM của các quốc gia khu vực Đông Nam Á. Vì vậy, mục đích của bài viết này là xem xét các yếu tố ảnh hưởng đến nợ xấu các ngân hàng khu vực Đông Nam Á với dữ liệu bảng bao gồm 204 ngân hàng giai đoạn từ năm 2010 đến năm 2015 tại 8 quốc gia trong khu vực.

Thư hai, hầu hết các nghiên cứu tại Việt Nam trước đây như Nguyễn Thị Ngọc Diệp và Nguyễn Minh Kiều (2015), Phan Đình Khôi và Nguyễn Việt Thành (2017) chỉ tập trung chủ yếu vào mối quan hệ giữa các yếu tố đặc thù của ngân hàng và nợ xấu. Do nghiên cứu trên nhiều quốc gia khác nhau, nghiên cứu này sẽ bổ sung ước lượng các yếu tố kinh tế vĩ mô tác động đến nợ xấu.

Cuối cùng, các kỹ thuật hồi quy dữ liệu bảng động được áp dụng để phân tích dữ liệu bảng của các NHTM và kiểm tra ảnh hưởng của nợ xấu trong quá khứ đến nợ xấu hiện lại.

Cấu trúc các phần tiếp theo của bài viết như sau: Phần 2 lược khảo các nghiên cứu trước đây về các yếu tố ảnh hưởng đến nợ xấu; phần 3 đề cập các phương pháp được sử dụng trong nghiên cứu; trong khi phần 4 mô tả dữ liệu được sử dụng; kết quả thực nghiệm được trình bày trong phần 5 ; và cuối cùng, phần 6 kết luận những phát hiện chính của bài nghiên cứu.

\section{Cơ sở lý thuyết}

Các lý thuyết nền tảng liên quan đến nợ xấu ngân hàng đều cho rằng nợ xấu bị ảnh hưởng bởi cả yếu tố đặc thù của ngân hàng và yếu tố kinh tế vĩ mô. Các yếu tố đặc thù của ngân hàng là kết quả trực tiếp của các quyết định quản lý, bao gồm khả năng sinh lời, vốn chủ sở hữu, chất lượng tài sản

\footnotetext{
${ }^{1}$ Bankscope Database (https://banks.bvdinfo.com)
} 
và quy mô ngân hàng. Các yếu tố kinh tế vĩ mô liên quan đến nợ xấu được sử dụng để đánh giá bao gồm: tăng trưởng kinh tế, lạm phát, thất nghiệp, thuế thu nhập và chính sách tài khóa.

\subsection{Anh hưởng của các yếu tố đặc thù của ngân hàng đến nợ xấu}

Các nghiên cứu gần đây về nợ xấu như Athanasoglou và cộng sự (2008), Anastasiou và cộng sự (2016), Louzis và cộng sự (2010), Podpiera và Weill (2008) đề cập đến yếu tố đặc thù của ngân hàng sử dụng các biến như: lợi nhuận, vốn chủ sở hữu, tăng trưởng tín dụng và quy mô ngân hàng. Giả thuyết quản lý kém do Berger và DeYoung (1997) đề xuất cho rằng hiệu quả quản lý thấp có mối quan hệ cùng chiều với sự gia tăng nợ xấu trong tương lai. Berger và DeYoung (1997) lý giải điều này thông qua sự yếu kém trong công tác quản lý cũng như các kỹ năng không đủ tốt trong việc chấm điểm tín dụng, thẩm định tài sản đảm bảo và cam kết giám sát khách hàng vay. Berger và DeYoung (1997) tìm thấy các bằng chứng thực nghiệm về giả thuyết quản lý kém, ngụ ý nguyên nhân từ hiệu quả thấp dẫn đến nợ xấu thông qua nghiên cứu các ngân hàng thương mại của Mỹ trong giai đoạn 1985-1994 và kết luận rằng các ngân hàng hoạt động kém hiệu quả dẫn đến gia tăng các khoản vay có vấn đề trong tương lai. Podpiera và Weill (2008) cũng kiểm định mối quan hệ giữa hiệu quả chi phí (Cost Efficiency) liên quan đến việc lựa chọn đầu vào (chẳng hạn: vốn và lao động) để tạo đầu ra với chi phí thấp nhất và nợ xấu trong khu vực ngân hàng Séc giai đoạn 1994-2005, và kết quả nghiên cứu ủng hộ giả thuyết quản lý kém, tức là hiệu quả chi phí thấp sẽ dẫn đến nợ xấu gia tăng. Bên cạnh đó, Salas và Saurina (2002), Klein (2013) xem xét mối quan hệ giữa nợ xấu trong quá khứ với nợ xấu hiện tại, và kết quả nghiên cứu ủng hộ giả thuyết quản lý nợ xấu trong quá khứ kém sẽ dẫn đến nợ xấu cao hơn trong tương lai.

Theo giả thuyết rủi ro đạo đức, Keeton và Morris (1987) cho rằng mức vốn hóa đóng vai trò quan trọng trong việc xác định mức độ nợ xấu mà cụ thể là khi mức vốn hóa thấp dễ làm tăng rủi ro của danh mục cho vay và do đó gia tăng nợ xấu. Keeton và Morris (1987) đã thực hiện nghiên cứu trên các NHTM Mỹ giai đoạn 1979-1985 thông qua việc chọn các biến nghiên cứu là tỷ suất sinh lợi trên tổng tài sản, quy mô ngân hàng, mức độ chịu rủi ro của ngân hàng thể hiện qua các biến là vốn chủ sở hữu trên tổng tài sản, dư nợ cho vay trên tổng tài sản để kiểm tra giả thuyết này; kết quả nghiên cứu cho thấy nợ xấu gia tăng đối với các ngân hàng có tỷ lệ vốn chủ sở hữu trên tài sản tương đối thấp. Mối liên hệ ngược chiều giữa nợ xấu và mức vốn hóa cũng đã được tìm thấy trong nghiên cứu của Berger và DeYoung (1997), Salas và Saurina (2002), Louzis và cộng sự (2010) cùng Stolz và Wedow (2011). Salas và Saurina (2002) kiểm tra các yếu tố quyết định khoản nợ xấu của các NHTM của Tây Ban Nha trong giai đoạn 1985-1997 đã kết luận rằng mức vốn hóa tác động ngược chiều đến nợ xấu là phù hợp với giả thuyết rủi ro đạo đức. Louzis và cộng sự (2010) cũng có kết luận tương tự đối với các ngân hàng Hy Lạp. Nghiên cứu của Hellmann và cộng sự (2000) cùng Stolz và Wedow (2011) cũng cho thấy nợ xấu tác động cùng chiều với hệ số an toàn vốn và giải thích rằng ngân hàng sử dụng vốn như một tấm đệm trước rủi ro danh mục đầu tư.

Giả thuyết chu kỳ tín dụng đề cập đến mối quan hệ giữa tăng trưởng tín dụng và nợ xấu. Theo đó, Keeton (1999) giải thích rằng các NHTM thường áp dụng chính sách tín dụng mở rộng trong thời kỳ tăng trưởng kinh tế và các tiêu chuẩn cấp tín dụng thường được nới lỏng, từ đó dễ dẫn đến nợ xấu gia tăng, và ngược lại, các NHTM áp dụng chính sách tăng trưởng tín dụng thắt chặt trong giai đoạn kinh tế suy giảm. Tuy nhiên, kết quả nghiên cứu thực nghiệm về mối quan hệ này không thống nhất với nhau: Trong khi mối quan hệ ngược chiều giữa tăng trưởng tín dụng và nợ xấu được tìm thấy trong các nghiên cứu của Louzis và cộng sự (2010), Le (2016), Jimenez và Saurina (2006) thì các nghiên 
cứu khác như Clair (1992), Keeton (1999), Demirgüç-Kunt và Detragiache (1998) cùng Foos và cộng sự (2010) lại cho thấy tăng trưởng cho vay có mối quan hệ cùng chiều với nợ xấu.

Giả thuyết hiệu ứng quy mô cho rằng chất lượng nợ của NHTM chịu ảnh hưởng bởi quy mô ngân hàng. Theo giả thuyết này, quy mô ngân hàng tác động ngược chiều đến nợ xấu. Do lợi thế nhờ quy mô, các ngân hàng lớn sẽ chịu chi phí thấp hơn trong việc quản lý và giám sát ngân hàng. Điều này giúp các ngân hàng lớn giảm rủi ro tín dụng phát sinh từ thông tin bất đối xứng giữa người cho vay và người vay. Kết quả các nghiên cứu thực nghiệm về mối quan hệ này cũng không thống nhất với nhau: Trong khi một số nghiên cứu cho thấy mối quan hệ cùng chiều giữa nợ xấu và quy mô ngân hàng, như: Louzis và cộng sự (2010), Das và Gosh (2007), Le (2016) thì các nghiên cứu khác lại tìm thấy bằng chứng quy mô ngân hàng có mối quan hệ ngược chiều đến nợ xấu, như Salas và Saurina (2002).

\subsection{Anh hương của các yếu tố vĩ mô của ngân hàng đến nợ xấu}

Nợ xấu không chỉ bị tác động bởi các yếu tố đặc thù của ngân hàng mà còn bị ảnh hưởng bởi các yếu tố kinh tế vĩ mô. Lý thuyết gia tốc tài chính được đề cập trong các nghiên cứu của Bernanke và Gertler (1989), Bernanke và Gilchrist (1999) cùng Kiyotaki và Moore (1997) là khung lý thuyết nổi bật nhất về mối liên kết giữa nền kinh tế vĩ mô và rủi ro tín dụng. Lý thuyết này giải thích rủi ro tín dụng và mối quan hệ của nó với những biến động mang tính chu kỳ trong nền kinh tế. Trong khi nền kinh tế tăng trưởng, tỷ lệ nợ xấu có xu hướng giảm do giá trị tài sản ròng của người đi vay tăng sẽ giúp cải thiện khả năng trả nợ của họ. Do đó, người cho vay sẽ ít gặp rủi ro hơn đối với khách hàng có giá trị tài sản ròng cao. Ngược lại, khi nền kinh tế xấu đi, tỷ lệ nợ xấu có xu hướng tăng do giá trị tài sản ròng của người đi vay giảm. Điều này là do sự suy giảm về giá trị tài sản đảm bảo, nên người cho vay thận trọng hơn, và do đó, tăng trưởng tín dụng có xu hướng giảm.

Các nghiên cứu thực nghiệm được nêu dưới đây có xu hướng kiểm định mối liên hệ giữa các yếu tố đại diện cho kinh tế vĩ mô và nợ xấu. Salas và Saurina (2002) kết luận tăng trưởng tổng sản phẩm quốc nội (GDP) tác động ngược chiều và có ý nghĩa thống kê đến nợ xấu của hệ thống ngân hàng Tây Ban Nha và suy ra việc truyền tải nhanh chóng của yếu tố kinh tế vĩ mô đến khả năng trả các khoản vay của các đối tượng trong nền kinh tế. Beck và cộng sự (2015) cho rằng các yếu tố quan trọng nhất ảnh hưởng đến nợ xấu là tăng trưởng GDP, giá cổ phiếu, lãi suất và tỷ giá hối đoái. Nkusu (2011) nhận định rằng tăng trưởng kinh tế suy giảm, cùng với tỷ lệ thất nghiệp cao hơn và giá tài sản giảm có liên quan đến việc nợ xấu gia tăng. Ngược lại, khi tăng trưởng kinh tế vĩ mô được cải thiện, điều này sẽ giúp giảm các khoản nợ xấu. Ghosh (2006) kết luận rằng các biến liên quan đến sự gia tăng của nợ xấu là thất nghiệp, lạm phát và nợ công tăng. Fofack (2005) cũng lưu ý rằng nợ xấu có thể được xác định bởi các yếu tố khác nhau, chẳng hạn như: GDP, lãi suất, tỷ giá hối đoái, lãi suất cho vay liên ngân hàng. Espinoza và Prasad (2010) cũng tìm thấy bằng chứng rằng nợ xấu giảm khi lãi suất tăng và nghiên cứu của Kauko (2012) cho thấy nợ xấu giảm khi thặng dư ngân sách (Fiscal) gia tăng. Louzis và cộng sự (2010) lưu ý rằng nợ xấu có liên quan đáng kể đến các yếu tố vĩ mô và chất lượng quản lý. Messai (2013) cũng kết luận tỷ lệ thất nghiệp và lãi suất thực ảnh hưởng cùng chiều đến nợ xấu. 


\section{Phương pháp nghiên cứu}

Dựa vào các nghiên cứu trước như: Salas và Sarina (2002), Louzis và cộng sự (2010), Anastasiou và cộng sự (2016) về tác động của các yếu tố đặc thù ngân hàng và kinh tế vĩ mô đến nợ xấu, tác giả áp dụng cách tiếp cận phân tích dữ liệu bảng động để giải thích cho sự tồn tại yếu tố thời gian trong tỷ lệ nợ xấu. Mối quan hệ giữa các yếu tố tác động và nợ xấu được xác định như phương trình (1) sau đây:

$$
N P L_{i t}=\alpha_{0}+\alpha_{1} N P L_{i t-1}+\beta M_{j t}+\pi F_{i t}+\varepsilon_{i t},|\alpha| \leq 1
$$

Trong đó, các kí hiệu i và t biểu thị đường chéo và chiều thời gian trong mẫu dữ liệu bảng tương ứng; $\varepsilon_{i t}=\llbracket \eta_{\mathrm{it}}+v \rrbracket$ với $\eta_{\mathrm{it}}$ là ảnh hưởng của các yếu tố đặc thù không quan sát được, $v$ là sai số; $M_{j t}$ đại diện các yếu tố kinh tế vĩ mô; $F_{i t}$ đại diện các yếu tố đặc thù của ngân hàng; $\alpha_{0}$ là hệ số chặn; các ký hiệu $\alpha_{1}, \beta, \pi$ lần lượt là hệ số tương quan giữa các biến nợ xấu trong quá khứ, các biến vĩ mô và các biến đặc thù với nợ xấu.

Để kiểm tra ảnh hưởng của nợ xấu trong quá khứ, nhóm tác giả sử dụng độ trễ của nợ xấu $\left(N P L_{i t-1}\right)$ làm biến giải thích và nghiên cứu kỳ vọng nợ xấu hiện tại có mối liên hệ cùng chiều có ý nghĩa thống kê với nợ xấu trong quá khứ.

Trong phương trình (1), các yếu tố đặc thù của ngân hàng $F_{i t}$ bao gồm biến đo lường hiệu quả hoạt động được tính bằng lợi nhuận sau thuế trên vốn chủ sở hữu $(\mathrm{ROE})$, biến đo lường vốn và khả năng thanh khoản được tính theo tỷ lệ vốn chủ sở hữu trên tổng tài sản và tỷ lệ dư nợ cho vay/ tổng vốn huy động, biến tăng trưởng tín dụng được xác định bởi phần trăm tăng trưởng tín dụng, và biến quy mô ngân hàng được tính bởi logarit tự nhiên của tổng tài sản. Các yếu tố kinh tế vĩ mô $M_{j t}$ bao gồm: GDP, lạm phát, số dư ngân sách (\% GDP), thuế thu nhập của cá nhân và doanh nghiệp (\% GDP), và tỷ lệ thất nghiệp.

Nghiên cứu này áp dụng dữ liệu bảng động hai bước được đề xuất bởi Arellano và Bover (1995) cùng Blundell và Bond (2000). Đồng thời, tác giả sử dụng kỹ thuật ước lượng moment tổng quát (GMM) để giải quyết các vấn đề nội sinh, phương sai thay đổi, và các vấn đề tương quan trong dữ liệu (Doytch \& Uctum, 2011). Kỹ thuật này đặc biệt thích hợp trong trường hợp hành vi kinh tế và tài chính đang bị ảnh hưởng phần lớn bởi những kinh nghiệm trong quá khứ và mô hình của hành vi cũ; do đó, quan hệ kinh tế hoặc tài chính của giá trị của các biến trễ được kiểm tra trong mô hình nghiên cứu. Phương pháp GMM tốt hơn phương pháp bình phương bé nhất (OLS) truyền thống trong việc kiểm tra mức độ biến động của các biến tài chính (Driffill \& cộng sự, 1998). Các nghiên cứu trước đây cho thấy rằng các biến đại diện cho yếu tố đặc thù của ngân hàng có thể có hiện tượng nội sinh (Athanasoglou \& cộng sự, 2008) và một số biến độc lập khác không ngoại sinh nghiêm ngặt. Do đó, nhóm tác giả lựa chọn sử dụng phương pháp GMM để kiểm định ảnh hưởng của các yếu tố kinh tế vĩ mô và yếu tố đặc thù ngân hàng đến nợ xấu, đồng thời, kiểm tra ảnh hưởng của nợ xấu trong quá khứ (biến trễ của nợ xấu) đối với nợ xấu hiện tại.

Bảng 2 thống kê các biến được sử dụng trong nghiên cứu này, trong đó, biến nợ xấu được thể hiện bằng tỷ lệ nợ xấu/tổng dư nợ. Các biến kinh tế vĩ mô bao gồm: Tốc độ tăng trưởng GDP thực tế hàng năm (GDPG), lạm phát được tính là sự thay đổi trung bình của chỉ số CPI (INF), thặng dư/thâm hụt ngân sách của Chính phủ tính bằng phần trăm GDP (FISCAL), thuế thu nhập tính bằng phần trăm GDP (TAXINC), và tỷ lệ thất nghiệp (UNEMP). 
Mối quan hệ của các biến và kỳ vọng nghiên cứu dựa trên các lý thuyết và giả thuyết đã trình bày ở Phần 2. Cụ thể, đối với các biến đặc thù ngân hàng, theo giả thuyết quản lý kém, ROE kỳ vọng ngược chiều với nợ xấu. Theo giả thuyết rủi ro đạo đức, vốn chủ sở hữu/tổng tài sản và dư nợ cho vay/vốn huy động tác động ngược chiều với nợ xấu. Tăng trưởng tín dụng kỳ vọng tác động cùng chiều với nợ xấu theo giả thuyết chu kỳ tín dụng. Quy mô ngân hàng tác động ngược chiều đến nợ xấu theo giả thuyết hiệu ứng quy mô.

Về các biến kinh tế vĩ mô, tăng trưởng kinh tế được kỳ vọng tác động ngược chiều với nợ xấu theo lý thuyết gia tốc tài chính đã giải thích ở phần trên. Lạm phát và thất nghiệp dự kiến sẽ có tác động ngược chiều với nợ xấu. Tỷ lệ lạm phát cao dẫn tới giảm thu nhập thực tế và có thể khiến lãi suất tăng làm ảnh hưởng đến khả năng trả nợ khiến mức độ nợ xấu lớn hơn (Klein, 2013; Nkusu, 2011). Thuế thu nhập kỳ vọng tác động cùng chiều với nợ xấu do khi thuế thu nhập tăng lên, thì thu nhập còn lại và khả năng trả nợ của người đi vay sẽ giảm xuống (Anastasiou \& cộng sự, 2016). Trong khi đó, ngân sách chính phủ kỳ vọng tác động cùng chiều đến nợ xấu do sự thay đổi tích cực của số dư ngân sách điều chỉnh theo chu kỳ (là kết quả của chính sách tài khóa thắt chặt) sẽ giới hạn các khoản vay đến các đối tượng trong nền kinh tế, từ đó sẽ ảnh hưởng đến khả năng trả nợ của người đi vay và sẽ làm nợ xấu gia tăng (Siakoulis, 2017; Anastasiou \& cộng sự, 2016).

\section{Bảng 2}

Mô tả các biến sử dụng trong mô hình nghiên cứu

\begin{tabular}{llclll}
\hline Phân loại & Tên biến & $\begin{array}{c}\text { Ký hiệu } \\
\text { biên }\end{array}$ & Cách đo lường & Nguồn \\
\hline $\begin{array}{l}\text { Các biến đặc thù } \\
\text { ngân hàng }\end{array}$ & Nợ xấu ngân hàng & NPL & Tỷ lệ nợ xấu/tổng dư nợ & Bankscope ${ }^{2}$ \\
& Hiệu quả ngân hàng & ROE & $\begin{array}{l}\text { Lợi nhuận sau thuế trên vốn chủ sở } \\
\text { hữu }\end{array}$ & \\
& Vốn chủ sở hữu & ETA & Vốn chủ sở hữu/tổng tài sản & \\
& Dư nợ cho vay & LTD & Dư nợ cho vay/vốn huy động & \\
& Tổng tài sản & LGR & Phần trăm tăng trưởng tín dụng & \\
& Tăng trưởng kinh tế & GDPG & $\begin{array}{l}\text { Tốc độ tăng trưởng kinh tế (GDP) } \\
\text { thực hàng năm }\end{array}$ & IMF ${ }^{3}$ \\
& Lạm phát & INF & Lạm phát theo chỉ số giá tiêu dùng & \\
& Số dư ngân sách & FISCAL & Ngân sách tính trên \% GDP & \\
& Thuế thu nhập & TAXINC & Thuế thu nhập tính \% GDP & \\
& Thất nghiệp & UNEMP & Tỷ lệ thất nghiệp & \\
\hline
\end{tabular}

\footnotetext{
${ }^{2}$ Bankscope Database (https://banks.bvdinfo.com)

${ }^{3}$ International Monetary Fund (IMF) data access to macroeconomic \& financial data (http://data.imf.org/?sk=edcb50d2-9c8a-4d3d-8b4f-190d2e4be644)
} 


\section{Mô tả các biến và nguồn dữ liệu}

Mô hình được kiểm định dựa trên dữ liệu bảng hàng năm của 204 NHTM tại 8 quốc gia khu vực Đông Nam Á, gồm có: Singapore, Malaysia, Indonesia, Philippines, Thái Lan, Việt Nam, Campuchia và Lào từ năm 2010 đến 2015. Dữ liệu thứ cấp được thu thập từ BankScope bao gồm 903 quan sát, còn dữ liệu kinh tế vĩ mô thu thập từ cơ sở dữ liệu của IMF (Bảng 2).

Bảng 3 báo cáo tóm tắt các số liệu thống kê cho giá trị lớn nhất, nhỏ nhất, trung bình và độ lệch chuẩn của các biến được sử dụng để ước tính các yếu tố tác động đến nợ xấu. Số liệu thống kê được tính toán từ dữ liệu hàng năm trong đó đơn vị tính của tất cả các biến được biểu thị bằng phần trăm. Từ bảng này, tỷ lệ nợ xấu từ $0,00 \%$ đến $101,22 \%$ và lợi nhuận trên vốn chủ sở hữu từ $-86,751 \%$ đến $82,786 \%$ cho thấy sự khác biệt về khả năng sinh lời của các ngân hàng là khác nhau. Bên cạnh đó, khoản dư nợ cho vay trên vốn huy động là rất cao ở mức là $102,857 \%$. Điều này cho thấy các ngân hàng khu vực Đông Nam Á vẫn phụ thuộc nhiều vào hoạt động cho vay. Tốc độ tăng trưởng GDP thể hiện mức độ tăng trưởng khác nhau giữa các nước, trong đó cao nhất là tốc độ tăng trưởng GDP của Singapore năm 2010 là 15,240\%, và thấp nhất là tốc độ tăng trưởng GDP của Thái Lan năm 2014 $(0,818 \%)$.

\section{Bảng 3.}

Thống kê mô tả các biến

\begin{tabular}{lccccc}
\hline Biến & Số quan sát & $\begin{array}{c}\text { Giá trị } \\
\text { trung bình }\end{array}$ & Độ lệch chuẩn & $\begin{array}{c}\text { Giá trị } \\
\text { nhỏ nhất }\end{array}$ & $\begin{array}{c}\text { Giá trị } \\
\text { lớn nhất }\end{array}$ \\
\hline NPL & 903 & 3,605 & 8,386 & 0,000 & 101,220 \\
ROE & 903 & 9,754 & 11,027 & $-86,751$ & 82,786 \\
ETA & 903 & 15,001 & 10,988 & 2,787 & 87,588 \\
LTD & 903 & 102,857 & 72,069 & 0,550 & 682,640 \\
LGR & 903 & 23,158 & 35,919 & $-64,050$ & 480,060 \\
InTA & 903 & 21,829 & 1,909 & 16,737 & 26,533 \\
GDPG & 903 & 5,584 & 1,772 & 0,818 & 15,240 \\
INF & 903 & 4,703 & 3,289 & $-0,895$ & 18,677 \\
FISCAL & 903 & $-3,119$ & 2,001 & $-12,400$ & 1,100 \\
UNEMP & 903 & 3,772 & 2,575 & 0,200 & 7,500 \\
TAXINC & 903 & 14,098 & 3,263 & 10,100 & 22,400 \\
\hline
\end{tabular}

Do dữ liệu bảng của nghiên cứu là không cân bằng, nhóm tác giả đã sử dụng kiểm định nghiệm đơn vị bằng kiểm định Dickey-Fuller Fisher Augmented. Giả thuyết $\mathrm{H}_{0}$ cho rằng tất cả các biến đều chứa nghiệm đơn vị tức là chuỗi dữ liệu không dừng. Các kết quả được trình bày trong Bảng 4 . Tất cả các biến được sử dụng có $\mathrm{p}$-value $<\alpha=1 \%$ và giá trị thống kê $\mathrm{ADF}>$ giá trị $\tau$ tới hạn nên bác bỏ giả thuyết $\mathrm{H}_{0}$, tức là chuỗi dữ liệu đều có tính dừng. 


\section{Bảng 4.}

Kiểm định nghiệm đơn vị

\begin{tabular}{lcc}
\hline Biến & $\begin{array}{c}\text { Giá trị p-value } \\
\text { Fisher type ADF }\end{array}$ & $\begin{array}{c}\text { Giá trị thống kê } \\
\text { Fisher type ADF }\end{array}$ \\
\hline NPL & 0,0000 & $-8,8598$ \\
ROE & 0,0000 & $-4,0812$ \\
ETA & 0,0000 & $-3,1995$ \\
LTD & 0,0000 & $-10,7507$ \\
LGR & 0,0000 & $-13,7412$ \\
lnTA & 0,0000 & $-2,0998$ \\
GDPG & 0,0000 & $-8,1288$ \\
INF & 0,0000 & 3,8010 \\
FISCAL & 0,0000 & $-24,2540$ \\
TAXINC & 0,0000 & 9,4175 \\
UNEMP & 0,0000 & $-19,9473$ \\
\hline
\end{tabular}

\section{Kết quả nghiên cứu}

Các mô hình khác nhau của phương trình (1) được kiểm định bao gồm:

Mô hình 1: $N P L_{i t}=\alpha_{0}+\alpha_{1} N P L_{i t-1}+\pi F_{i t}+\varepsilon_{i t}$

Trong đó, $F_{i t}$ là các yếu tố đặc thù của ngân hàng i trong năm $\mathrm{t}$. Mô hình 1 ước lượng các yếu tố đặc thù tác động đến nợ xấu của các NHTM khu vực Đông Nam Á theo như các giả thuyết đã đề cập.

Mô hình 2: $\quad N P L_{i t}=\alpha_{0}+\alpha_{1} N P L_{i t-1}+\pi F_{i t}+\pi_{1} F_{i t-1}+\varepsilon_{i t}$

Trong đó, $F_{i t-1}$ là biến trễ của các yếu tố đặc thù của ngân hàng i trong năm $\mathrm{t}$. Mô hình 2 ước lượng các yếu tố đặc thù cùng với độ trễ của các biến đặc thù của ngân hàng thương mại đến nợ xấu của các NHTM khu vực Đông Nam Á.

Mô hình 3: $\quad N P L_{i t}=\alpha_{0}+\alpha_{1} N P L_{i t-1}+\beta M_{j t}+\varepsilon_{i t}$

Trong đó, $M_{j t}$ là yếu tố kinh tế vĩ mô của quốc gia $\mathrm{j}$ trong năm $\mathrm{t}$. Mô hình 3 ước lượng tác động của các biến kinh tế vĩ mô đến nợ xấu của các NHTM khu vực Đông Nam Á.

Mô hình 4: $N P L_{i t}=\alpha_{0}+\alpha_{1} N P L_{i t-1}+\beta M_{j t}+\beta_{1} M_{j t-1}+\varepsilon_{i t}$

Trong đó, $M_{j t-1}$ là biến trễ của yếu tố kinh tế vĩ mô. Mô hình 4 sẽ ước lượng các yếu tố kinh tế vĩ mô cùng với độ trễ của các biến này đến nợ xấu của của các NHTM khu vực Đông Nam Á.

Mô hình 5: $\quad N P L_{i t}=\alpha_{0}+\alpha_{1} N P L_{i t-1}+\beta M_{j t}+\pi F_{i t}+\varepsilon_{i t}$

Mô hình 5 trình bày kết quả tác động của cả biến đặc thù của ngân hàng và biến kinh tế vĩ mô đến nợ xấu của các NHTM khu vực Đông Nam Á. 
Mô hình 6: $\quad N P L_{i t}=\alpha_{0}+\alpha_{1} N P L_{i t-1}+\beta M_{j t}+\beta_{1} M_{j t-1}+\pi F_{i t}+\pi_{1} F_{i t-1}+\varepsilon_{i t}$

Mô hình 6 trình bày kết quả tổng hợp của tác động của cả biến đặc thù của ngân hàng và biến kinh tế vĩ mô và độ trễ của các biến này đến nợ xấu của các NHTM khu vực Đông Nam Á.

Kết quả ước lượng GMM cho các mô hình được trình bày trong Bảng 5 , theo đó, kết quả này cho thấy tác động tương ứng của các yếu tố ảnh hưởng đến nợ xấu.

\section{Bảng 5.}

Kết quả ước lượng GMM các yếu tố ảnh hưởng đến nợ xấu các ngân hàng thương mại khu vực Đông Nam Á, giai đoạn 2010-2015

\begin{tabular}{|c|c|c|c|c|c|c|}
\hline Biến & Mô hình 1 & Mô hình 2 & Mô hình 3 & Mô hình 4 & Mô hình 5 & Mô hình 6 \\
\hline$N P L_{i t-1}$ & $\begin{array}{c}0,6797 * * * \\
(0,0051)\end{array}$ & $\begin{array}{c}0,5826 * * * \\
(0,0043)\end{array}$ & $\begin{array}{c}0,6487 * * * \\
(0,0063)\end{array}$ & $\begin{array}{c}0,8719^{* * *} \\
(0,0203)\end{array}$ & $\begin{array}{c}0,6544 * * * \\
(0,0021)\end{array}$ & $\begin{array}{c}0,6335^{* * *} \\
(0,0021)\end{array}$ \\
\hline ROE & $\begin{array}{c}-0,0198^{*} \\
(0,0074)\end{array}$ & $\begin{array}{c}-0,0937 * * * \\
(0,0143)\end{array}$ & & & $\begin{array}{c}-0,0120^{* * * *} \\
(0,0020)\end{array}$ & $\begin{array}{c}-0,0561 * * * \\
(0,0043)\end{array}$ \\
\hline $\mathrm{ROE}_{\mathrm{it}-1}$ & & $\begin{array}{c}-0,0393 * * \\
(0,0137)\end{array}$ & & & & $\begin{array}{c}0,0526 * * * \\
(0,0067)\end{array}$ \\
\hline ETA & $\begin{array}{c}0,0466^{* * *} \\
(0,0084)\end{array}$ & $\begin{array}{c}0,0357 \\
(0,0359)\end{array}$ & & & $\begin{array}{c}0,0635 * * * \\
(0,0039)\end{array}$ & $\begin{array}{c}0,1123 * * * \\
(0,0117)\end{array}$ \\
\hline ETA $_{\text {it }-1}$ & & $\begin{array}{l}-0,0766 \\
(0,0360)\end{array}$ & & & & $\begin{array}{c}-0,0395 * * \\
(0,0132)\end{array}$ \\
\hline LTD & $\begin{array}{c}-0,0052 * * * \\
(0,0012)\end{array}$ & $\begin{array}{c}-0,0132 * * * \\
(0,0017)\end{array}$ & & & $\begin{array}{c}-0,0059 * * * \\
(0,0006)\end{array}$ & $\begin{array}{c}-0,0081 * * * \\
(0,0025)\end{array}$ \\
\hline LTD $_{\text {it }-1}$ & & $\begin{array}{c}0,0066^{* * *} \\
(0,0018)\end{array}$ & & & & $\begin{array}{c}0,0021 \\
(0,0016)\end{array}$ \\
\hline LGR & $\begin{array}{c}-0,0616^{* * *} \\
(0,0045\end{array}$ & $\begin{array}{c}-0,0366^{* * *} \\
(0,0057)\end{array}$ & & & $\begin{array}{c}-0,0360 * * * \\
(0,0007)\end{array}$ & $\begin{array}{c}-0,0394 * * * \\
(0,0018)\end{array}$ \\
\hline LGR $_{\mathrm{it}-1}$ & & $\begin{array}{c}-0,0100 * * * \\
(0,0017)\end{array}$ & & & & $\begin{array}{c}0,0136 * * * \\
(0,0007)\end{array}$ \\
\hline $\operatorname{lnTA}$ & $\begin{array}{c}-0,2858 * * * \\
(0,0619)\end{array}$ & $\begin{array}{l}0,06935 \\
(0,7024)\end{array}$ & & & $\begin{array}{c}-0,2284 * * * \\
(0,0364)\end{array}$ & $\begin{array}{c}-0,455 \\
(0,2886)\end{array}$ \\
\hline $\ln \mathrm{TA}_{\mathrm{it}-1}$ & & $\begin{array}{l}-0,2836 \\
(0,6857)\end{array}$ & & & & $\begin{array}{c}0,1834 \\
(0,2880)\end{array}$ \\
\hline GDPG & & & $\begin{array}{c}-0,1467 * * * \\
(0,0409)\end{array}$ & $\begin{array}{c}-0,0964 * * \\
(0,0340)\end{array}$ & $\begin{array}{c}-0,0810^{* * *} \\
(0,0149)\end{array}$ & $\begin{array}{c}-0,1418 * * * \\
(0,0248)\end{array}$ \\
\hline $\mathrm{GDPG}_{\mathrm{it}-1}$ & & & & $\begin{array}{c}-0,1162 * * * \\
(0,0331)\end{array}$ & & $\begin{array}{c}0,0555 * * * \\
(0,017)\end{array}$ \\
\hline INF & & & $\begin{array}{l}0,0564 * \\
(0,0216)\end{array}$ & $\begin{array}{c}0,0503 * * \\
(0,0175)\end{array}$ & $\begin{array}{c}0,0051 \\
(0,0080)\end{array}$ & $\begin{array}{l}-0,0257 \\
(0,0113)\end{array}$ \\
\hline
\end{tabular}




\begin{tabular}{|c|c|c|c|c|c|c|}
\hline Biến & Mô hình 1 & Mô hình 2 & Mô hình 3 & Mô hình 4 & Mô hình 5 & Mô hình 6 \\
\hline $\mathrm{INF}_{\mathrm{it}-1}$ & & & & $\begin{array}{c}0,1279 * * * \\
(0,0279)\end{array}$ & & $\begin{array}{l}-0,0380 \\
(0,0167)\end{array}$ \\
\hline FISCAL & & & $\begin{array}{c}-0,1935^{* * *} \\
(0,0598)\end{array}$ & $\begin{array}{c}0,0564 \\
(0,0550)\end{array}$ & $\begin{array}{c}-0,0691 * * * \\
(0,0049)\end{array}$ & $\begin{array}{c}-0,0837 * * \\
(0,0270)\end{array}$ \\
\hline FISCALit-1 & & & & $\begin{array}{l}-0,0608 \\
(0,5840)\end{array}$ & & $\begin{array}{c}0,047 \\
(0,0219)\end{array}$ \\
\hline TAXINC & & & $\begin{array}{l}-0,1013 \\
(0,0497)\end{array}$ & $\begin{array}{l}-0,0140 \\
(0,0856)\end{array}$ & $\begin{array}{c}0,1240 * * * \\
(0,01293)\end{array}$ & $\begin{array}{l}-0,0495 \\
(0,0336)\end{array}$ \\
\hline TAXINC $_{\mathrm{it}-1}$ & & & & $\begin{array}{l}-0,0917 \\
(0,0770)\end{array}$ & & $\begin{array}{c}0,2263 * * * \\
(0,0370)\end{array}$ \\
\hline UNEMP & & & $\begin{array}{c}0,0814 \\
(0,0636)\end{array}$ & $\begin{array}{l}0,4181 * \\
(0,1556)\end{array}$ & $\begin{array}{c}0,3371 * * * \\
(0,02568)\end{array}$ & $\begin{array}{c}0,4559 * * * \\
(0,0852)\end{array}$ \\
\hline UNEMP $_{\text {it-1 }}$ & & & & $\begin{array}{c}-0,4541 * * \\
(0,1533)\end{array}$ & & $\begin{array}{l}-0,0870 \\
(0,0789)\end{array}$ \\
\hline Hệ số chặn & $\begin{array}{c}8,5471 * * * \\
(1,4580)\end{array}$ & $\begin{array}{c}9,2280 * * * \\
(2,2121)\end{array}$ & $\begin{array}{c}2,0878 * * \\
(0,7301)\end{array}$ & $\begin{array}{c}2,1810 * * * \\
(0,4632)\end{array}$ & $\begin{array}{c}3,9292 * * * \\
(0,8075)\end{array}$ & $\begin{array}{c}4,0543 * * * \\
(1,1536)\end{array}$ \\
\hline Số quan sát & 692 & 692 & 692 & 692 & 692 & 692 \\
\hline Số ngân hàng & 204 & 204 & 204 & 204 & 204 & 204 \\
\hline Prob>chi2 & 0,000 & 0,000 & 0,000 & 0,000 & 0,000 & 0,000 \\
\hline Kiểm định Hansen & 0,101 & 0,210 & 0,391 & 0,118 & 0,358 & 0,442 \\
\hline Kiểm định AR(1) & 0,004 & 0,006 & 0,014 & 0,021 & 0,007 & 0,003 \\
\hline Kiểm định AR(2) & 0,338 & 0,327 & 0,352 & 0,366 & 0,348 & 0,340 \\
\hline
\end{tabular}

Ghi chú: *,**, *** lần lượt tương ứng với các mức ý nghĩa thống kê $10 \%, 5 \%$ và $1 \%$.

Giá trị trong dấu ngoặc đơn ( ) là sai số chuẩn.

Kết quả ước lượng trong Bảng 5 cho thấy rằng cả hai yếu tố đặc thù ngân hàng và yếu tố kinh tế vĩ mô đều đóng vai trò quan trọng ảnh hưởng đến nợ xấu của các ngân hàng khu vực Đông Nam Á. Kết quả cũng thể hiện giá trị hệ số tương quan cao giữa nợ xấu trong quá khứ và nợ xấu hiện tại. Hệ số độ trễ của NPL trong khoảng từ 0,5826 đến 0,8719 , cho thấy một cú sốc đối với nợ xấu có khả năng ảnh hưởng lâu dài đến hệ thống ngân hàng ở khu vực Đông Nam Á.

Đối với các biến giải thích khác, tỷ suất lợi nhuận của ngân hàng tác động ngược chiều đến nợ xấu và có ý nghĩa thống kê trong tất cả các mô hình, kết quả này hỗ trợ giả thuyết quản lý kém của Berger và DeYoung (1997). Điều này hàm ý rằng khi các NHTM ở khu vực Đông Nam Á quản lý kém dẫn đến các hoạt động dễ xảy ra rủi ro và nợ xấu gia tăng hơn. Ngược lại, các NHTM có mức sinh lời cao ít tham gia các hoạt động cho vay mang tính rủi ro và do đó nợ xấu giảm. Khả năng chịu rủi ro của ngân hàng thể hiện qua tỷ lệ vốn chủ sở hữu trên tài sản tác động cùng chiều và tỷ lệ cho vay/tiền gửi ảnh hưởng đến nợ xấu của các ngân hàng ở khu vực Đông Nam Á trong hầu hết các mô hình. Tỷ lệ cho vay/tiền gửi hiện tại tác động ngược chiều đến nợ xấu, tuy nhiên, trong mô hình 2 , 
biến trễ của tỷ lệ cho vay/tiền gửi tác động cùng chiều với nợ xấu, điều này cho thấy khi cho vay tăng thì nợ xấu cũng gia tăng nhưng có độ trễ theo thời gian. Kết quả nghiên cứu chỉ ra hệ số tương quan của vốn chủ sở hữu trên tổng tài sản cùng chiều với nợ xấu khác với giả thuyết rủi ro đạo đức, tuy nhiên, biến trễ của vốn chủ sở hữu lại có mối quan hệ ngược chiều với nợ xấu. Điều này được giải thích rằng theo thời gian, các NHTM ở khu vực Đông Nam Á nào có mức vốn hóa thấp thì rủi ro danh mục cho vay gia tăng và do đó làm nợ xấu tăng. Sự thay đổi trong tổng dư nợ/vốn huy động cũng ảnh hưởng đến nợ xấu ở mức ý nghĩa $1 \%$. Tác động ngược chiều của tăng trưởng tín dụng và tỷ lệ cho vay/tiền gửi đến nợ xấu khác với giả thuyết chu kỳ tín dụng. Điều này hàm ý việc tăng trưởng tín dụng thấp sẽ khiến người đi vay khó tiếp cận với khoản vay hơn và khả năng trả nợ của họ giảm dẫn đến nợ xấu tăng (Keeton, 1999). Kết quả ước lượng đối với biến tổng tài sản cung cấp bằng chứng mạnh mẽ ủng hộ giả thuyết hiệu ứng quy mô, được xác định bởi các hệ số có ý nghĩa thống kê về tổng tài sản trong mô hình 1 và mô hình 5 .

Trong số các biến kinh tế vĩ mô, biến GDPG có ảnh hưởng ngược chiều và có ý nghĩa thống kê đến nợ xấu trong tất cả các mô hình. Điều này hàm ý tỷ lệ nợ xấu dự kiến cao hơn khi nền kinh tế xấu đi liên quan đến sự suy giảm của dòng tiền của người đi vay và giá trị tài sản ròng, làm giảm khả năng trả nợ của họ (Le, 2016). Tỷ lệ lạm phát và thất nghiệp ở cả năm hiện tại $\mathrm{t}$ và năm trước $\mathrm{t}-1$ được tìm thấy có mối quan hệ cùng chiều với nợ xấu. Ngoài ra, biến ngân sách ảnh hưởng ngược chiều và có ý nghĩa thống kê đến nợ xấu trong hầu hết các mô hình. Điều này hàm ý thặng dư ngân sách sẽ tác động ngược chiều đến nợ xấu ở các NHTM Đông Nam Á, khác với kỳ vọng ban đầu của nghiên cứu. Trong mô hình 5 và mô hình 6 , kết quả nghiên cứu cũng tìm thấy rằng biến thuế thu nhập và biến độ trễ của thuế thu nhập có ảnh hưởng cùng chiều có ý nghĩa thống kê đến nợ xấu. Điều này phù hợp với nghiên cứu của Anastasiou và cộng sự (2016). Mối quan hệ này được giải thích là khi thuế thu nhập tăng lên, thu nhập còn lại và khả năng trả nợ của người đi vay sẽ giảm xuống.

Kết quả nghiên cứu cho thấy kiểm định Hansen của các mô hình đều có p-value $>0,1$, tức là chấp nhận giả thuyết $\mathrm{H}_{0}$, trong đó, giả thuyết $\mathrm{H}_{0}$ cho rằng biến công cụ là ngoại sinh, nghĩa là không tương quan với sai số của mô hình. Kiểm định $\mathrm{AR}(2)$ có $\mathrm{p}$-value $>0,1$ nghĩa là chấp nhận giả thuyết $\mathrm{H}_{0}$. Giả thuyết $\mathrm{H}_{0}$ của kiểm định $\mathrm{AR}(2)$ là không có hiện tượng tự tương quan bậc 2 trong mô hình. Như vậy, kết quả các mô hình đều cho thấy các công cụ của mô hình là phù hợp và không có hiện tượng tự tương quan trong mô hình.

\section{Kết luận và hàm ý chính sách}

Nghiên cứu thực hiện việc kiểm định tác động của các yếu tố đến nợ xấu dựa trên mẫu là 204 NHTM của 8 quốc gia khu vực Đông Nam Á. Áp dụng các kỹ thuật dữ liệu bảng động với ước lượng GMM hệ thống, kết quả thực nghiệm cung cấp một số bằng chứng để xác nhận rằng cả hai nhóm các yếu tố đặc thù ngân hàng và yếu tố kinh tế vĩ mô đều đóng vai trò quan trọng trong việc tác động khiến nợ xấu gia tăng của các ngân hàng khu vực Đông Nam Á. Kết quả cho thấy nợ xấu cao trong giai đoạn hiện tại là do tác động bởi nợ xấu trong quá khứ, tỷ suất lợi nhuận thấp, tăng trưởng tín dụng thấp, vốn chủ sở hữu cao và quy mô ngân hàng lớn. Ngoài ra, các yếu tố kinh tế vĩ mô có ảnh hưởng đáng kể đến chất lượng cho vay của ngân hàng. Kết quả cũng cho thấy biến chính sách tài khóa có tác động ngược chiều đến nợ xấu và có ý nghĩa thống kê. Kết quả này sẽ hữu ích cho các nhà hoạch định chính sách để thiết kế các chính sách tài khóa và bình ổn kinh tế vĩ mô. Nghiên cứu này cho thấy 
việc đánh giá rủi ro tín dụng cần được chú trọng khi thiết kế các chính sách kinh tế vĩ mô, do đó, các nhà hoạch định chính sách không chỉ nên tập trung vào các yếu tố hiệu quả vĩ mô mà còn chú trọng các ảnh hưởng quan trọng của các yếu tố vĩ mô đến khu vực tài chính ngân hàng. Nghiên cứu cũng làm sáng tỏ mối quan hệ giữa các yếu tố kinh tế vĩ mô, ngân sách, thuế thu nhập và các yếu tố ngân hàng, điều này sẽ giúp phát triển các mô hình kiểm tra căng thẳng cho việc quản lý rủi ro tín dụng.

Dựa vào kết quả thực nghiệm, nghiên cứu đề xuất các hàm ý chính sách quan trọng:

Đầu tiên, mối quan hệ ngược chiều giữa nợ xấu và khả năng sinh lời cho thấy rằng các cơ quan quản lý nên áp dụng việc kiểm tra và theo dõi rủi ro của khoản nợ ngân hàng một cách chặt chẽ hơn.

Thư hai, biến trễ của vốn chủ sở hữu tác động ngược chiều đến nợ xấu đã cho thấy tỷ lệ vốn thấp có thể gia tăng rủi ro và khiến nợ xấu gia tăng. Do đó, việc đảm bảo yêu cầu tỷ lệ vốn dựa trên rủi ro cũng sẽ giúp ngăn chặn hành vi cho vay quá mức đối với các ngân hàng có rủi ro cao.

Thứ $b a$, các NHTM khu vực Đông Nam Á cần cải thiện cơ chế quản lý và kiểm soát rủi ro, từ đó sẽ hạn chế các khoản vay quá hạn và nợ xấu.

Hạn chế của nghiên cứu là chưa phân loại các ngân hàng theo quy mô hoặc mức tăng trưởng của các ngân hàng khác nhau trên thị trường, cũng như phân loại các khoản nợ xấu của các NHTM khu vực Đông Nam Á. Nghiên cứu cũng không đi sâu vào đặc điểm của các NHTM tại các quốc gia khác nhau mà chỉ xem xét các yếu tố tác động đến nợ xấu trên mẫu như các chỉ số cảnh báo. Trong các nghiên cứu tiếp theo, nhóm tác giả kỳ vọng sẽ xem xét các yếu tố tác động đến nợ xấu bằng cách phân loại theo quy mô của ngân hàng và mức độ tăng trưởng của các ngân hàng khác nhau trên thị trường.

\section{Lời cảm ơn}

Bài viết này chuyển ngữ từ phiên bản tiếng Anh: "Determinants of non-performing loans: Evidence from Southeast Asian countries” đã được công bố trong Kỷ yếu Hội thảo Quốc tế International Conference of University of Economics Ho Chi Minh City (ICUEH2017) với chủ đề "Policies and Substainable Economic Development" tổ chức vào tháng 9/2017. Nhóm tác giả gửi lời cảm ơn Ban Tổ chức Hội thảo ICUEH2017 và Ban biên tập Tạp chí Nghiên cứu Kinh tế và Kinh doanh Châu Á đã tạo điều kiện và chấp thuận đưa vào quy trình phản biện kín nhằm giúp tác giả hoàn thiện bài viết với chất lượng tốt nhất

\section{Tài liệu tham khảo}

Anastasiou D., Louri H., \& Tsionas M. (2016). Determinants of non-performing loans: Evidence from Euro-area countries. Finance Research Letters, 18(C), 116-119.

Arellano, M., \& Bover, O. (1995). Another look at the instrumental-variable estimation of errorcomponents. Journal of Econometrics, 68(1), 29-52.

Athanasoglou, P., Brissimis, S. N., \& Delis, M. D. (2008). Bank-specific, industry-specific and macroeconomic determinants of bank profitability. Journal of International Financial Markets, Institutions and Money, 18(2), 121-136.

Beck, R., Jakubik, P., \& Piloiu, A. (2015). Key determinants of non-performing loans: new evidence from a global sample. Open Economies Review,26(3), 525-550. 
Berger, A. N., \& DeYoung, R. (1997). Problem loans and cost efficiency in commercial banks, Journal of Banking and Finance, 21(6), 849-870.

Bernanke, B., \& Gertler, M. (1989). Agency costs, net worth and business fluctuations. American Economic Review, 79(1), 14-31.

Bernanke, B., \& Gilchrist, S. (1999). The financial accelerator in a quantitative business cycle framework. Handbook of Macroeconomics, 1C, 1341-1393.

Blundell, R., \& Bond, S. (2000). GMM estimation with persistent panel data: An application to production functions. Econometric Reviews, 19(3), 321-340.

Clair, R. T. (1992). Loan growth and loan quality: Some preliminary evidence from Texas banks. Economic Review, Federal Reserve Bank of Dallas, Third Quarter, 9-22.

Demirgüç-Kunt, A., \& Detragiache, E. (1998). The determinants of banking crises in developing and developed countries. Staff Papers, 45(1), 81-109.

Das, A., \& Ghosh, S. (2007). Determinants of credit risk in indian state-owned banks: An empirical investigation. Economic Issues Journal Articles, 12(2), 27-46.

Doytch, N., \& Uctum, M. (2011). Does the worldwide shift of FDI from manufacturing to services accelerate economic growth? A GMM estimation study. Journal of International Money and Finance, 30(3), 410-427.

Driffill, J., Psaradakis, Z., \& Sola, M. (1998). Testing the expectations hypothesis of the term structure using instrumental variables. International Journal of Finance and Economics, 3(4), 321-325.

Espinoza, R., \& Prasad, A. (2010). Non-performing Loans in the GCC Banking System and their Macroeconomic Effects. IMF Working Paper: Non-performing Loans in the GCC Banking System and their Macroeconomic Effects, 10(224).

Fofack, H. (2005). Non-performing loans in sub-saharan africa: Causal analysis and macroeconomic implications. World Bank Policy Research Working, Paper 3769.

Foos, D., Norden, L., \& Weber, M. (2010). Loan growth and riskiness of banks. Journal of Banking \& Finance, 34(12), 2929-2940.

Ghosh, S. (2005). Does leverage influence banks' non-performing loans? Evidence from India. Applied Economics Letters, 12(15), 913-918.

Hellmann, T. F., Murdock, K. C., \& Stiglitz, J. E. (2000). Liberalization, moral hazard in banking, and prudential regulation: Are capital requirements enough? American Economic Review, 90(1), $147-165$.

Jimenez, G., \& Saurina, J. (2006). Credit Cycles, Credit Risk, and Prudential Regulation. International Journal of Central Banking, 2(2), 65-98.

Kauko, K. (2012). External deficits and non-performing loans in the recent financial crisis. Economics Letters, 115, 196-199.

Keeton, W. R. (1999). Does faster loan growth lead to higher loan losses? Economic Review-Federal Reserve Bank of Kansas City, 84(2), 57-76.

Keeton, W. R., \& Morris, C. (1987). Why Do Banks' Loan Losses Differ? Federal Reserve Bank of Kansas City Economic Review, 72(5), 3-21. 
Kiyotaki, N., \& Moore, J. (1997). Credit Cycles, Journal of Political Economy, 105(2), 211-247.

Klein, N. (2013). Non-performing loans in CESEE: Determinants and Impact on Macroeconomic Perfomance. IMF Country Report, No. 13/72. Retrieved from https://www.imf.org/en/Publications/WP/Issues/2016/12/31/Non-Performing-Loans-in-CESEEDeterminants-and-Impact-on-Macroeconomic-Performance-40413

Le, H. A. C. (2016). Macro-financial linkages and bank behaviour: Evidence from the second-round effects of the global financial crisis on East Asia. Eurasian Economic Review, 6(3), 365-387.

Louzis, D., Vouldis, A., \& Metaxas, V. (2010). Macroeconomic andbank-specific determinants of non-performing loans in Greece: A comparative study of mort-gage, business and consumer loan portfolios. Journal Banking and Finance, 36(4), 1012-1027.

Messai, A. (2013). Micro and macro determinants of non-performing loans. International Journal of Economics and Finance, 3(4), 852-860.

Nkusu, M. (2011). Non-performing loans and macrofinancial vulnerabilities in Advanced Economies. IMF Working Paper, 11/161. Retrieved from https://www.imf.org/external/pubs/cat/longres_gsause.aspx?sk=25026\&gsa=true

Nguyễn Thị Ngọc Diệp, \& Nguyễn Minh Kiều. (2015). Ảnh hưởng của yếu tố đặc điểm đến rủi ro tín dụng ngân hàng thương mại Việt Nam. Tạp chí Phát triển kinh tế, 26(3), 49-63.

Phan Đình Khôi, \& Nguyễn Việt Thành. (2017). Các yếu tố vi mô ảnh hưởng đến rủi ro tín dụng: Trường hợp các ngân hàng thương mại cổ phần sở hữu nhà nước ở Hậu Giang. Tạp chí Khoa học Đại học Cần Tho, 48, 104-111.

Podpiera, J., \& Weill, L. (2008). Bad luck or bad management? Emerging banking market experience. Journal of Financial Stability, 4(2), 135-148.

Salas, V., \& Saurina, J. (2002). Credit risk in two institutional regimes: Spanish commercial and savings banks. Journal of Financial Services Research, 22(3), 203-224.

Siakoulis, V. (2017). Fiscal policy effects on non-performing loan formation, Working Paper 224. Bank of Greece. Retrieved from https://www.bankofgreece.gr/BogEkdoseis/Paper2017224.pdf

Stolz, S., \& Wedow, M. (2011). Banks' regulatory capital buffer and the business cycle: Evidence for Germany. Journal of Financial Stability, 7(2), 98-110.

Windmeijer, F. (2005). A finite sample correction for the variance of linear efficient two-step GMM estimators. Journal of Econometrics, 126(1), 25-51. 